\title{
Social inequalities in causes of death amenable to health care in Norway
}

\author{
Camilla Hem ${ }^{1}$, Øyvind Næss ${ }^{1,2,3}$ and Bjørn Heine Strand ${ }^{3}$ \\ 1) Institute of General Practice and Community Medicine, University of Oslo, Norway \\ 2) Institute of Health Management and Health Economics, University of Oslo, Norway \\ 3) Norwegian Institute of Public Health, Oslo, Norway \\ Correspondence: camilla.hem@studmed.uio.no
}

\begin{abstract}
Objective: Investigate if there are educational inequalities in causes of death considered amenable to health care in Norway and compare this with non-amenable causes. Methods: The study used the concept of "amenable mortality", which here includes 34 specific causes of death. A linked data file, with information from the Norwegian Causes of Death Registry and the Educational Registry was analyzed. The study population included the whole Norwegian population in two age groups of interest (25-49 and 50-74 years). Information on deaths was from the period 1990-2001. Education was recorded in 1990 and it was grouped in four categories as: basic, lower secondary, higher secondary and higher. In the study men and women were analysed seperately. The analysis was conducted for all amenable causes pooled with and without ischemic heart disease. A Cox proportional hazard regression model was fitted to estimate hazard rate ratios. Results: The study showed educational differences in mortality from causes of death considered amenable to health care, in both age groups and sexes. This was seen both when including and excluding ischemic heart disease. The effect sizes were comparable for amenable and non-amenable causes in both age groups and sexes. Conclusions: This study revealed systematic higher risk of death in lower educational groups in causes of death considered amenable to health care. This indicates potential weaknesses in equitable provision of health care for the Norwegian population. Additional research is needed to identify domains within the health care system of particular concern.
\end{abstract}

\section{INTRODUCTION}

Social inequalities in health have been reported in a number of Norwegian and international studies $(1,2)$. The relative inequalities in Norway appear similar or comparable in size to the ones found in other countries in Western Europe.

Several approaches have been developed in attempts to quantify the performance of the health care system (3-6). One approach widely used employ the readily availability of mortality data at a population level and is based on the concept that deaths from certain causes should not occur in the presence of timely and effective health care (7). Causes of death considered amenable to health care is analysed to assess whether differences in treatment and care within the health care system contribute to socioeconomic inequalities in health. This has given rise to the development of a variety of terms including "mortality amenable to health care" and "avoidable mortality", which were first coined by Rutstein in 1976. It is considered reasonable to believe that effective treatment or primary or secondary prevention could be provided by health services, although there is considerable controversy over the avoidability of death from some causes, for example congenital anomaly (8). Consequently, it was assumed that while not all deaths from causes considered amenable to health care would be avoidable, health care could contribute substantially to mini- mising mortality. Some causes, such as coronary heart disease, are still considered only partially amenable to medical care. While some causes are more closely related to primary care, others are more related to secondary care or prevention and health policy, such as vaccination.

The concept "mortality amenable to health care" has been used as a measure for the quality of health care systems and to asses the effectiveness of health care over time and within and between countries (8). However it must be recognised that the concept does have important limitations relating to comparability of data, attribution of causes and coverage of the range of health outcomes. Amenable mortality was probably never intended to be more than an indicator of potential weakness in health care that then can be investigated in more depth.

Internationally, several studies have documented social inequalities in health and mortality. This is found in both causes considered amenable and nonamenable to health care. One study by Mackenbach and colleagues was carried out with material from the period between 1931 and 1981 in England and Wales and between 1952 and 1982 in The Netherlands (9). In this period amenable mortality declined faster than allcause mortality in England and Wales. The decline was generally greater among the higher social classes and they concluded that health care contributed to the observed widening of mortality differences between 
socioeconomic groups. Further they concluded that differences in decline in mortality from amenable causes were probably due, at least in part and at least up to 1960 , to differences between socio-economic groups in accessibility, utilization or quality of medical care. In a case-control study of regional and social class differences in Finland, in 1980-1986, Poikolainen and Eskola demonstrated a significantly elevated risk of death from amenable causes for those in the lowest occupational category compared with the highest category (10). They concluded that the lower social groups seemed to delineate a deprived group likely to need special help from health care. This population group was deprived either in access, utilization or quality of health care received in the City of Helsinki.

Other international studies and additional research suggest a fairly consistent pattern, where those grouped as being socially disadvantaged are at a higher risk of death from amenable causes (11-13). Conclusions converge despite some differences in methodology, location, time and in definitions of socioeconomic or demographic factors. Furthermore, these findings were consistent regardless of which component of socioeconomic position (education, occupation or income) was used. The only exception is one study by Westerling and colleagues which found only small differences in amenable mortality between blue and white collar workers (8). There was, however, an almost three-fold statistically significant difference in mortality due to gastric and duodenal ulcer. They also reported significantly higher death rates among those not in the workforce, which were three-times those of the working population.

In Norway earlier studies have mostly looked at inequalities in consumption of health services. A study by Kravdal has found that people with a higher level of education who are diagnosed with cancer survive longer than those with less education (14). Also, a study in another Nordic country, Denmark, shows that a low level of education and a low income increases mortality risk (15).

Inequalities in health and mortality in Norway have recently in a Report to the Storting been described and declared as unacceptable when they are unjust, avoidable and unnecessary (16). Norway also has national laws for securing the right of patients (17).

This study aimed to assess whether there are educational inequalities in causes of death considered amenable and non-amenable to health care in Norway. Studies based on the method of amenable mortality have to our knowledge never before been done in Norway.

\section{METHODS}

We used data from the Norwegian Causes of Death Registry and the Educational Registry. Missing data are infrequent in these registers. The study population included the whole Norwegian population in the age- groups 25-49 years and 50-74. Information on deaths is from the period November 3, 1990 to December 31, 2001. There were no limitations as to where these individuals lived before 1990 and after 2001. As long as they were Norwegian citizens in the current period they were registered. Education was registered from 1990.

The Causes of Death Registry is based upon the death certificates routinely issued by doctors following the deaths of all Norwegian citizens. The certificate states the underlying cause of death and up to six contributory causes (18). For the years 1990-1995 causes of death were coded according to the Ninth Revision of the International Classification of Diseases (ICD 9), and for the years 1996-2001 the Tenth Revision of the International Classification of Diseases (ICD 10) was used. The data linkage was done by Statistics Norway. The underlying cause of death is used consistently and it is defined by the WHO as (a): "the disease or injury which initiated the train of morbid events leading directly to death", or (b): "the circumstances of the accident or violence which produced the fatal injury". There are certain rules for selection of the underlying cause and in certain cases there are modification rules defining which diagnosis should be given preference (18).

Education was coded in four categories: 1) basic ( $\leq 9$ years), 2) lower secondary (10 years), 3 ) higher secondary (11-12 years), 4) higher (13+ years). The Norwegian Educational Registry includes information on all Norwegian citizens. The study makes use of education as an indicator because it is stable and not subject to temporary or permanent changes by disability, unemployment or retirement.

The definition of "amenable to health care" has changed somewhat over the years, as knowledge of the effects of medical treatment on the population has evolved. Recent advances in specific treatments may similarly have complicated the use of this concept in the study of the issue over time. Myocardial infarction has for example probably changed both in incidence as well as in case fatality rate, suggesting more effective treatment may have contributed to the decline in mortality rates (8). The deaths were grouped according to the list provided by Nolte and McKee (8) (table 1). The authors used this list in a comparative study published in the British Medical Journal and as a report by the Nuffield Trust. This list was constructed based on earlier lists such as the ones by Mackenbach and Charlton $(9,19)$. Recent medical advances and the greater life expectancy have been taken into account. Because it is uncertain if ischemic heart disease is amenable and because it is a major cause of death, the analyses were done with and without ischemic heart disease. Men and women were analyzed separately.

The association between mortality and educational lenght adjusted for age was measured by hazard ratio (HR) estimated in a Cox regression model using STATA software. Age at the 1990 Census was treated as a continuous variable. 
Table 1. Causes of death considered amenable to medical treatment and the ICD-codes for these causes.

\begin{tabular}{|c|c|c|}
\hline Cause of death & ICD-9 & ICD-10 \\
\hline Intestinal infections & $001-9$ & A00-9 \\
\hline Tuberculosis & $010-8,137$ & A15-9, B90 \\
\hline Other infections (diphtheria, tetanus, poliomyelitis) & $032,037,045$ & A 36, A35, A80 \\
\hline Whooping cough & 033 & A37 \\
\hline Septicaemia & 038 & A40-1 \\
\hline Measles & 055 & B05 \\
\hline Malignant neoplasm of colon and rectum & $153-4$ & $\mathrm{C} 18-21$ \\
\hline Malignant neoplasm of skin & 173 & $\mathrm{C} 44$ \\
\hline Malignant neoplasm of breast & 174 & $\mathrm{C} 50$ \\
\hline Malignant neoplasm of cervix uteri & 180 & $\mathrm{C} 53$ \\
\hline Malignant neoplasm of cervix uteri and body of uterus & 179,182 & $\mathrm{C} 54, \mathrm{C} 55$ \\
\hline Malignant neoplasm of testis & 186 & C62 \\
\hline Hodgkin's disease & 201 & $\mathrm{C} 81$ \\
\hline Leukaemia & $204-8$ & C91-5 \\
\hline Diseases of the thyroid & $240-6$ & E00-7 \\
\hline Diabetes mellitus & 250 & E10-4 \\
\hline Epilepsy & 345 & G40-1 \\
\hline Chronic rheumatic heart disease & $393-8$ & I05-9 \\
\hline Hypertensive disease & $401-5$ & $\mathrm{I} 10-3, \mathrm{I} 15$ \\
\hline Cerebrovascular disease & $430-8$ & I60-9 \\
\hline All respiratory diseases (excluding pneumonia and influenza) & $460-79,488-519$ & J00-9, J20-99 \\
\hline Influenza & 487 & $\mathrm{~J} 10-1$ \\
\hline Pneumonia & $480-6$ & $\mathrm{~J} 12-8$ \\
\hline Peptic ulcer & $531-3$ & $\mathrm{~K} 25-7$ \\
\hline Appendicitis & $540-3$ & $\mathrm{~K} 35-8$ \\
\hline Abdominal hernia & $550-3$ & K40-6 \\
\hline Cholelithiasis and cholecystitis & $574-5.1$ & K80-1 \\
\hline Nephritis and nephrosis & $580-9$ & N00-7, N17-9, N25-7 \\
\hline Benign prostatic hyperplasia & 600 & $\mathrm{~N} 40$ \\
\hline Maternal death & $630-76$ & O00-99 \\
\hline Congenital cardiovascular anomalies & $745-7$ & Q20-8 \\
\hline Perinatal deaths, all causes, excluding stillbirths & $760-79$ & P00-96, A33 \\
\hline Misadventures to patients during surgical and medical care & E870-6, E878-9 & Y60-9, Y83-4 \\
\hline Ischemic heart disease & $410-4$ & $\mathrm{I} 20-5$ \\
\hline
\end{tabular}

\section{RESULTS}

Table 2 shows the number of individuals and time at risk by different levels of education and age groups. In the the age group 25-49 years a larger section of the population have higher education, compared to the population in the age group 50-74 years. Missing data are infrequent. In the age group $25-49$ years only $3.7 \%$ of men and $3.0 \%$ of women miss data. In the age group $50-74$ years only $2.0 \%$ of men and $1.6 \%$ of women miss data.

Table 3 shows age adjusted hazard ratios and number of deaths in causes amenable (with and without ischemic heart disease) and non-amenable to medical health care. It also shows age adjusted hazard ratios and number of deaths for total deaths. In men, amenable deaths comprised $31 \%$ of total deaths for the youngest age group. Without IHD, the percentage was reduced to $14 \%$. The corresponding numbers for the oldest age group were $55 \%$ and $30 \%$. In women amenable deaths comprised $42 \%$ of total deaths for the youngest age group. Without IHD, the percentage was reduced to $37 \%$. The corresponding numbers for the oldest age group was $58 \%$ and $38 \%$.

Less educated groups have generally higher number of deaths in both age groups and sexes compared to more educated groups. This result is consistent for all deaths and for amenable and non-amenable conditions.

A stepwise pattern of the four educational-groups (higher, higher secondary, lower secondary, basic) is consistent. The educational differences in mortality from causes of death considered amenable to health care are seen both when including and excluding ischemic heart disease. The effect sizes are comparable for amenable and non-amenable causes in both age groups and sexes.

For men in the youngest age group, those with the 
Table 2. Number of individuals (\%) and time at risk by person years and different levels of education and age-groups, in men and women.

\begin{tabular}{llcccc}
\hline & & \multicolumn{2}{c}{ Men } & \multicolumn{2}{c}{ Women } \\
\cline { 3 - 5 } Age-group & Education & Number & $\begin{array}{c}\text { Time at risk } \\
\text { (by person years) }\end{array}$ & Number & $\begin{array}{c}\text { Time at risk } \\
\text { (by person years) }\end{array}$ \\
\hline $25-49$ & Higher & $190669(24 \%)$ & 2044090 & $175530(24 \%)$ & 1896387 \\
& Higher secondary & $253502(32 \%)$ & 2768848 & $151873(20 \%)$ & 1662233 \\
& Lower secondary & $169738(22 \%)$ & 1850972 & $253224(34 \%)$ & 2786867 \\
& Basic & $138675(18 \%)$ & 1502350 & $138154(19 \%)$ & 1512470 \\
& Missing & $29262(3.7 \%)$ & & $22592(3.0 \%)$ & \\
Total & $781846(100 \%)$ & & $741373(100 \%)$ & \\
& Higher & $79803(14 \%)$ & 771340 & $54363(8 \%)$ & 544946 \\
& Higher secondary & $113096(20 \%)$ & 1058742 & $42770(6 \%)$ & 417418 \\
& Lower secondary & $114169(20 \%)$ & 1036796 & $202971(29 \%)$ & 1961732 \\
& Basic & $259694(45 \%)$ & 2186505 & $389924(56 \%)$ & 3486868 \\
& Missing & $11568(2.0 \%)$ & & $11454(1.6 \%)$ & \\
Total & $578330(100 \%)$ & & $701482(100 \%)$ & \\
\hline
\end{tabular}

Table 3. Age adjusted hazard ratios (HR) with $95 \%$ confidence intervals $(95 \% \mathrm{CI})$ and number of deaths in causes amenable (with and without ischemic heart disease), non-amenable and for total deaths, in two different age groups, in men and women.

\begin{tabular}{|c|c|c|c|c|c|c|c|c|}
\hline \multirow[b]{2}{*}{ Education } & \multicolumn{2}{|c|}{ Total deaths } & \multicolumn{2}{|c|}{ Amenable with IHD } & \multicolumn{2}{|c|}{ Amenable without IHD } & \multicolumn{2}{|c|}{ Non-amenable } \\
\hline & $\operatorname{HR}(95 \% \mathrm{CI})$ & $\begin{array}{c}\text { Number of } \\
\text { deaths }\end{array}$ & $\operatorname{HR}(95 \% \mathrm{CI})$ & $\begin{array}{c}\text { Number of } \\
\text { deaths }\end{array}$ & $\operatorname{HR}(95 \% \mathrm{CI})$ & $\begin{array}{c}\text { Number of } \\
\text { deaths }\end{array}$ & $\operatorname{HR}(95 \% \mathrm{CI})$ & $\begin{array}{c}\text { Number of } \\
\text { deaths }\end{array}$ \\
\hline \multicolumn{9}{|l|}{ Men } \\
\hline \multicolumn{9}{|l|}{$25-49$} \\
\hline Higher & 1.00 & 3088 & 1.00 & 943 & 1.00 & 469 & 1.00 & 2145 \\
\hline Higher secondary & $1.41(1.35-1.47)$ & 5194 & $1.30(1.27-1.33)$ & 1604 & $1.22(1.18-1.26)$ & 725 & $1.29(1.26-1.31)$ & 3590 \\
\hline Lower secondary & $2.06(1.97-2.15)$ & 5654 & $1.38(1.35-1.41)$ & 1728 & $1.34(1.30-1.38)$ & 815 & $1.34(1.31-1.37)$ & 3926 \\
\hline Basic & $2.63(2.52-2.75)$ & 6532 & $1.64(1.61-1.67)$ & 2084 & $1.53(1.49-1.57)$ & 867 & $1.58(1.55-1.62)$ & 4448 \\
\hline \multicolumn{9}{|l|}{$50-74$} \\
\hline Higher & 1.00 & 20042 & 1.00 & 10176 & 1.00 & 5591 & 1.00 & 9866 \\
\hline Higher secondary & $1.22(1.20-1.24)$ & 35618 & $1.26(1.23-1.29)$ & 18784 & $1.22(1.18-1.26)$ & 10011 & $1.17(1.15-1.20)$ & 16834 \\
\hline Lower secondary & $1.27(1.25-1.29)$ & 41345 & $1.35(1.32-1.38)$ & 22481 & $1.29(1.25-1.34)$ & 12067 & $1.19(1.16-1.22)$ & 18864 \\
\hline Basic & $1.46(1.44-1.48)$ & 120243 & $1.57(1.54-1.60)$ & 67241 & $1.50(1.45-1.54)$ & 36596 & $1.35(1.32-1.38)$ & 53002 \\
\hline \multicolumn{9}{|l|}{ Women } \\
\hline \multicolumn{9}{|l|}{$25-49$} \\
\hline Higher & 1.00 & 1834 & 1.00 & 794 & 1.00 & 763 & 1.00 & 1040 \\
\hline Higher secondary & $1.22(1.14-1.31)$ & 1609 & $1.20(1.16-1.23)$ & 702 & $1.12(1.08-1.17)$ & 626 & $1.31(1.27-1.33)$ & 907 \\
\hline Lower secondary & $1.39(1.32-1.47)$ & 4353 & $1.23(1.20-1.26)$ & 1830 & $1.17(1.14-1.21)$ & 1611 & $1.30(1.27-1.33)$ & 2523 \\
\hline Basic & $1.99(1.88-2.10)$ & 3817 & $1.48(1.44-1.51)$ & 1560 & $1.34(1.31-1.38)$ & 1252 & $1.50(1.47-1.54)$ & 2257 \\
\hline \multicolumn{9}{|l|}{$50-74$} \\
\hline Higher & 1.00 & 10651 & 1.00 & 5876 & 1.00 & 4186 & 1.00 & 4775 \\
\hline Higher secondary & $1.12(1.09-1.15)$ & 10760 & $1.13(1.09-1.17)$ & 6017 & $1.10(1.06-1.15)$ & 4185 & $1.10(1.06-1.15)$ & 4743 \\
\hline Lower secondary & $1.16(1.13-1.18)$ & 54480 & $1.18(1.15-1.21)$ & 30715 & $1.12(1.09-1.16)$ & 20877 & $1.13(1.10-1.17)$ & 23765 \\
\hline Basic & $1.35(1.32-1.38)$ & 151340 & $1.42(1.38-1.45)$ & 88560 & $1.30(1.26-1.34)$ & 57952 & $1.27(1.23-1.30)$ & 62780 \\
\hline
\end{tabular}

lowest level of education had 1.64 times higher risk of death from amenable causes (including ischemic heart disease) than those with the highest level of education. The result for men in the oldest age group was 1.57 times higher risk of death for those in the lowest educational group compared to those in the highest group. Women had somewhat lower educational inequalities in mortality than men.

\section{DISCUSSION}

The study results indicate educational inequalities in mortality. The analysis reveal systematic higher age adjusted hazard ratios for lower educational groups in men and women both in causes amenable as well as in causes considered non-amenable to health care. The effect sizes are comparable for amenable and non- 
amenable causes in both age groups and sexes. Studies based on the method of amenable mortality have to our knowledge never before been done in Norway.

The study have some strengths and weaknesses: Missing data are infrequent in the registers used. Additionally, the study includes to total Norwegian population of interest. The concept "mortality amenable to health care" remove causes considered non-amenable to health care and use specific causes of death aiming to assess whether the health care system contributes to social inequalities in mortality. However, "amenable mortality" was never intended to be more than an indicator of potential weaknesses in health care that then can be investigated in more depht (8). The educational differences in hazard ratios from amenable causes in this study cannot give us information about whether the health care system contributes to increased or decreased social inequalities in mortality. The differences in the analysis may just, in part or fully, reflect educational differences in health conditions, differences in timing of treatment, differences in compliance to treatment or differences in life style patterns relevant for survival. The hazard ratios from causes considered non-amenable to health care show similar educational differences and indeed suggest that such differences are present in the population. The differences in hazard ratios from causes considered amenable to health care may also in part be due to a suboptimal organization of the health care system, resulting in population groups being deprived in access, utilization or quality of health care. Further research is needed to provide a better understanding of the potential factors. Some earlier investigations do suggest that higher edu- cational groups have bettter access to general health care and make more use of medical specialists in Norway $(20,21)$.

Publications, such as a report by the Directorate for health and social affairs (22) and the 2000 World health report by the World Health Organisation (4), as well as subsequent methodological work by OECD (5), have in recent time contributed to place the issue of health care performance on the national and international policy agenda. In the 1960 s and 1970 s commentators argued that health care had a very low impact on population health compared to individual health $(23,24)$. However, they were writing about a period when health care had relatively little to offer compared to today (25). While health care may have made little contribution to population health and mortality in the past it may now be playing a more important role.

The size of inequalities in mortality in causes considered amenable to health care is in this study comparable to inequalities in mortality in non-amenable causes. Further, there is a systematic higher risk of death in lower educational groups in causes of death considered amenable to health care. This indicates potential weaknesses in equitable provision of health care for the Norwegian population. The term "inequalities" is in this study used in a purely descriptive sense. It is not intended to convey any message directly on the fairness (26). Further research is needed to get more knowledge about the mechanisms and to convey any message directly on the fairness. Additional research is also needed to identify domains within the health care system of particular concern.

\section{REFERENCES}

1. Mackenbach JP, Kunst AE, Cavelaars AEJ, Groenhof F, Geurts JJM, the EU Working Group on Socioeconomic Inequalities in Health. Socioeconomic inequalities in morbidity and mortality in Western Europe. Lancet 1997; 349: 1655-9.

2. Krokstad S, Kunst AE, Westin S. Trends in health inequalities by educational level in a Norwegian total population study. J Epidemiol Community Health 2002; 56: 375-80.

3. McKee M. Measuring the efficiency of health systems. BMJ 2001; 323: 295-6.

4. World Health Organisation. The World Health Report 2000. Health Systems: Improving performance. Geneva: WHO, 2000.

5. Organisation for Economic Co-Operation and Development (OECD). Measuring up. Improving health system performance in OECD countries. Paris: OECD, 2002.

6. Nolte E, McKee M. Measuring the health of nations: analysis of mortality amenable to health care. $B M J 2003$; 327: 1129-34.

7. Rutstein DD, Berenberg W, Chalmers TC, Child CG, Fishman AP, Perrin EB. Measuring the quality of medical care: revision of tables of indexes. N Engl J Med 1977; 297: 508.

8. Nolte E, McKee M. Does health care save lives? Avoidable mortality revisited. London: Nuffield Trust for research and policy studies in health services, 2004.

9. Mackenbach JP, Stronks K, Kunst AE. The contribution of medical care to inequalities in health: differences between socio-economic groups in decline of mortality from conditions amenable to medical intervention. Soc Sci Med 1989; 29: 369-76.

10. Poikolainen K, Eskola J. Regional and social class variation in the relative risk of death from amenable causes in the city of Helsinki, 1980-1986. Int J Epidemiol 1995; 24: 114-8. 
11. Song Y-M, Byeon JJ. Excess mortality from avoidable and non-avoidable causes in men of low socioeconomic status: a prospective study in Korea. J Epidemiol Community Health 2000; 54: 166-72.

12. Wood E, Sallar AM, Schechter MT, Hogg RS. Social inequalities in male mortality amenable to medical intervention in British Columbia. Soc Sci Med 1999; 48: 1751-8.

13. Józan P, Forster DP. Social inequalities and health: ecological study of mortality in Budapest, 1980-3 and 1990-3. BMJ 1999; 318: 914-5.

14. Kravdal Ø. Social inequalities in cancer survival. Tidsskr Nor Laegeforen 1999; 119: 1577-83.

15. Rasmussen JN, Rasmussen S, Gislason GH, Buch P, Køber L, Osler M, Diderichsen F, Pedersen CT, Madsen M. Mortality after acute myocardial infarction according to income and education. J Epidemiol Community Health 2006; 60: 351-6.

16. Stortingsmelding nr. 20 (2006-2007). Nasjonal strategi for å utjevne sosiale helseforskjeller.

17. LOV 1999-07-02 nr 63: Lov om pasientrettigheter (pasientrettighetsloven).

18. Westerling R. "Avoidable" causes of death in Sweden 1974-85. Qual Assur Health Care 1992; 4: 319-28.

19. Charlton JRH, Velez R. Some international comparisons of mortality amenable to medical intervention. $B M J$ 1986; 292: 295-301.

20. Carlsen S. Geografisk fordeling av helsetilstand og allmennlegetilbud. Økonomisk Forum 2006 (2): 1-12.

21. Iversen T, Kopperud GS. Regulation versus practice: the impact of accessibility on the use of specialist health care in Norway. Health Econ 2005; 14: 1231-8.

22. Sund ER, Krokstad S. Sosiale ulikheter i helse i Norge, en kunnskapsoversikt (In Norwegian). Oslo: the Directorate for Health and Social Affairs, 2005.

23. Cochrane AL, St Leger AS, Moore F. Health service "input" and mortality "output" in developed countries. $J$ Epidemiol Community Health 1978; 32: 200-5.

24. Colgrove J. The McKeown thesis: a historical controversy and its enduring influence. Am J Public Health 2002; 92: 725-9.

25. Bunker JP. The role of medical care in contributing to health improvements within societies. Int J Epidemiol 2001; 30: 1260-3.

26. Mackenbach JP, Kunst AE. Measuring the magnitude of socio-economic inequalities in health: an overview of available measures illustrated with two examples from Europe. Soc Sci Med 1997; 44: 757-71. 